\title{
Communication in formal and non-formal science
}

\author{
AUTORES \\ Jordi Colomer Feliu
}

Full Professor, orcid.org/0000-0002-9330-0269, jordi.colomer@udg.edu

Physics Department, Escola Politècnica Superior, Universitat de Girona

https://www.udg.edu/ca/directori/pagina-personal?ID=52003

www.movimentlantana.com

Teresa Serra

Associate Professor, orcid.org/0000-0002-6075-5849 teresa.serra@udg.edu

Physics Department, Escola Politècnica Superior, Universitat de Girona

https://www.udg.edu/ca/directori/pagina-personal?ID = 2000723

www.movimentlantana.com

\begin{abstract}
Communication in both formal and non-formal education requires specific spaces, communicators and activities. Communication in formal science is highly regulated by research needs and the purposes of higher education institutions. In non-formal science, communication is more intrinsic, voluntary and typically non-sequential, given that it is a function of activities designed in out-of-school environments. In both cases, communication is linked to learning and is mediated by individual or community engagement and the need for constant dialogue between communicators and public and by the need to constantly design new architectures of interaction.
\end{abstract}

Keywords: science communication, formal education, non-formal education, community engagement, out-of-school labs, museums.

\section{Abstract}

La comunicación en la educación formal y no formal requiere espacios, comunicadores y actividades específicos. La comunicación en ciencia formal está altamente regulada por las necesidades de la investigación y por los objetivos de las instituciones de educación superior. En ciencia no formal, la comunicación es más intrínseca, voluntaria y, por lo general, no secuencial, dado que es una función de las actividades diseñadas en entornos fuera de la escuela. En ambos casos, la comunicación está vinculada al aprendizaje y está mediada por el compromiso individual o comunitario y la necesidad de un diálogo constante entre los comunicadores y el público y por la necesidad de diseñar constantemente formas nuevas de interacción.

Palabras clave: comunicación científica, educación formal, educación no formal, compromiso comunitario, laboratorios extraescolares, museos. 


\section{Introduction}

If science is to exist and persist, it must be communicated via channels and in spaces adapted to each circumstance and methodology. Science, tied to scientific research, in any field, be it humanistic, social, scientific, artistic and so on, or what derives from synergies between these fields, must be designed with a dual intention: first, to contribute to building knowledge and second, to be effective, reproducible and transforming.

The contribution scientific research makes to building knowledge occurs within well-defined structures, where objectives and challenges linked to discovering new objectives, objectives that imply a willingness to transform all previous knowledge, are defined. Scientific research must also be genuine, reproducible and contextualised (Hooke, 2015) and ethical and sustainable criteria must be applied in its development. And what is more, it must also be transforming: it must want to break away from the known and explore new frontiers; it must be compatible with the needs of ecosystems (educational, social, natural, among others); and it must respond to a willingness to progress, to constantly reinvent and to come up with new ideas. And last, any scientific research that had been designed, constructed, contextualised and concluded must be communicated with all these criteria.

The initial hypothesis of this article, then, is based on the precept that all science that wishes to be transformative must be cross-cutting and should be communicated effectively. By bringing together ideas and synthesizing connected theories and concepts, communication can overcome the lack of reach in science today; it can become a locus amoenus where rigorous, comprehensive statements and exploration merge (Entman, 1993). As Vorderer (2016) points out, communicating is becoming increasingly narrow in the sense that scientists tend to limit their scope of interest to the areas, theories and methodologies they are most familiar with and effort needs to be made to work in both in a more interdisciplinary and a more international way. In addition, in today's society, science communication venues should look increasingly less like museums and science centres or festivals, and become more like research facilities (Merzagora, 2017). And finally, both formal and non-formal communication should be defined in relation to the actors to whom it is addressed. Even though the communication of science is universal, there is a need to understand science so that it functions for active citizens (Rusell 2010): there is a need to design new platforms and spaces for engagement, and citizen enthusiasm needs to be constantly renewed for open science activities (Stilgoe et al. 2014). There is a positive correlation between high-quality community engagement and positive public attitudes towards science research at the moment new findings are revealed to the public (Pham 2016). With this in mind, the present article aims to explore the channels that effectively and efficiently communicate science in formal and non-formal environments and to illustrate the state of the art and the problems associated with communicating science in these domains.

\section{Analysis of communication in formal science.}

Scientific communication in formal domains has a clearly defined space and channels with well-known standards and scales to publish quality research. All scientific magazines, conferences and journals are monitored by prestigious scientific committees who define the priority lines of research that give the publications their uniqueness and some fixed, monitored publication regulations. The most highly regarded journals, those that are internationally considered as excellent, are decided by measuring their impact level in relation to other publications (the 
impact index, the h-index, etc), so they are classified according to well-defined positional scales for each scientific field. The countries that are classified as excellent in research are those that occupy high positions according to common scales. To give some examples, the 2016 Scimago ranking based on analysis of the research articles published from a specific country, placed Spain twelfth out of 239 countries in the $\mathrm{H}$ index among countries like Australia, Sweden, Belgium and China; and regarding citations per document, Spain was positioned 62nd out of the same 239 countries, among the countries Tonga, Cambodia, Sao Tome and Principe and the Federated States of Micronesia. With respect to the $\mathrm{H}$ number, in the specific fields of environmental sciences and social sciences, Spain is in 11th place between Sweden and Italy and in 13th place between Denmark and Hong Kong, respectively. But with respect to the number of citations per article, and again in environmental sciences and social sciences, Spain is 32nd between New Zealand and Barbados and 118th among countries like Paraguay, France and Sierra Leone, respectively.

In recent years, proposals to classify universities and research centres, which in theory detect the state of the art in science in each country around the world, have become popular. No longer is just the degree of research of an institute or university (based on first level articles and the number of citations) considered, as is the case with the SCIMAGO Institutions Rankings, but more global indicators such as teaching, knowledge transfer, professional orientation and the impact of the research on regional development are increasingly entering the analysis, as is the case with the CYD Ranking. The calculation of the impact of a publication is transparent and universal and as such determines many local, national and international policies. The capacity to publish in the world's best journals, those that occupy the highest positions, is not only linked to the ability to communicate well, but also to the resources that a line of research has at its disposal. In other words, the projects and lines of research with larger budgets are also the ones with the most well-defined lines of dissemination and publication. The publication of research articles in open access journals is increasing and this communication policy is only possible for centres with the biggest budgets. If we take a look at rankings, however, Catalan and Spanish scientific research in some areas of knowledge is not communicated well enough. Specialist publications circulate in a closed loop and for most authors, scientific communication does not leave the sphere of higher education. Access to these journals is closed and impractical. This is especially because of the way research is communicated, as all researchers must ensure the rigorousness and universality of what they want to communicate. This is why the scientific community must escape from this closed system, which entails changing how research is communicated, and especially, knowing the public to whom it is communicated.

In formal domains, quality research must be carried out that produces results in the form of publications and, what is more, this research must be communicated by presenting it at conferences, conventions, symposiums and so on. It is important that this affirmation is made effective, given that in the university domain there is an intrinsic link between research and applying this research to teaching and so if there is quality research, then the teaching is also likely to be of a high quality, and vice-versa. Nonetheless, in teaching domains of the education system, be it primary or secondary school, research into new ways of communicating knowledge must find its own universality and rigorousness, which requires effort on the part of the teachers that transcends personal goals or the aims of a specific centre. In this case, the public to whom the 
science is communicated is limited, and yet there is virtually no link ensuring that the scientific research produced in research centres filters through to these primary and secondary schools. Policies implemented by universities are defined with a unilateral vision and universities and research centres do not guarantee the social commitment required to do the research. And what is more, teachers do not have a structural design that gives them constant access to the knowledge generated at universities. Channels and spaces to communicate scientific research are few, unstructured and lacking the right agents to optimise this communication. Some policies worth highlighting, on the other hand, are those implemented by the Spanish Foundation for Science and Technology (FECYT), whose priority is to increase scientific culture and its dissemination and to communicate scientific knowledge by maximising the involvement of all the possible social agents that promote public participation.

The international actions and policies of specialist agencies and companies should be transferred to local agents linked to the territory. But, while in the formal domain defined in higher education centres the spaces and channels of scientific communication and the agents who manage this are known, in the education ecosystem it is not clear which agent or agents must be responsible for scientific communication and research. Furthermore, if there are agents responsible for research and teaching, to optimise results there ought to be agents specialised in scientific communication. If, over the last few years, universities have created scientific communication units so that the scientific research they carry out reaches the sphere of primary and secondary schools, then not only must the optimal spaces to disseminate science in both universities and other teaching centres be defined, but also who must be responsible for this communication. The dissemination of scientific knowledge is too often considered as a voluntary action and not one that merits a social service.

\section{Analysis of communication in non-formal science.}

It is the duty of the entities that generate the science to disseminate it to the society. There must be constant feedback between the producers of science and society. Transmitting and transferring knowledge and responsible innovation are vectors that have been shown to be of enormous value to the progress of society and individual learning (Owen et al. 2012). No individual will be able to meet life's challenges unless they become a lifelong learner (Plavsic and Dokovic, 2016) and education is a significant part of lifelong learning. What science contributes must be understood by collective, educational and individual ecosystems so that each of these subsystems have the tools to transform itself. To give an example, society needs to know how climate change will affect ecosystems on a planetary scale, which varieties there will be at each latitude and longitude and what the predictions over time will be. But primary and secondary schools and universities must also have the tools to debate critically, to know what the global and local repercussions of climate change will be and to devise strategies to mitigate these changes; and even more importantly, to determine what actions can be carried out on an individual level to combat climate change. In other words, use must be made of scientific knowledge not only in formal domains (universities, research institutes, secondary schools, primary schools, and so on), but also in non-formal domains.

The spread of scientific knowledge to non-formal domains implies the concept of educational institutions' service to society (Colardyn and Bjornavold 2004). All higher education institutions ought to commit to promoting the so-called learning service, which implies conceding the 
knowledge generated in higher education institutions to society. Conceding this knowledge is especially sensitive when political decisions must be made. More than half of all political decisions are based in scientific knowledge and they are decided by policymakers who are not scientists. Based on managing this knowledge, some of these agents determine the political policies that directly affect society. This is why the channels of scientific communication between the generators of knowledge and the managers, communicators and executors of the policies derived from it must be well regulated. An example of good regulation is that provided by the Intergovernmental Panel on Climate Change (IPCC) established in 1988 by the World Meteorological Organization (WMO) and the United Nations Environment Programme (UNEP). The IPCC provides comprehensive assessments on climate change, most recently the 2013 Fifth Assessment Report (AR5). More than 450 lead authors compile information provided by more than 800 contributing authors and 2,500 experts review the draft documents that effectively communicate the science, a technical report and a summary for policymakers. While the first is compiled from an extensive, transparent, iterative peer review process, the second is an effective adaptation of the scientific, technical and socioeconomic information to help private stakeholders, governments and NGOs to understand the risk of human-induced climate change. On the other hand, what happened at the ASCÓ nuclear plant when they reported a secondary internal problem is an example of failed regulation. The exact issue was not reported and 40 secondary school-age pupils and three teachers from Maristes School in Girona who had visited the plant on the previous 4th April had to have a radiological check-up examination to see if they had been affected by a radioactive leak. Society reacted very negatively to the lack of accuracy in the reporting and the facts were magnified because of the partial information released.

Communication and learning in non-formal domains can be compared to communication and learning in informal domains. In non-formal domains, which are usually institutions other than schools, both learning and communication is supportive, structured, usually prearranged and voluntary, typically non-sequential and the motivation may be extrinsic but is more usually intrinsic (Eshach 2007). On the other hand, learning and motivation in informal domains is based on activities that can be done anywhere, activities that are unstructured, spontaneous, totally voluntary, non-sequential and the motivation is mainly intrinsic (Eshach 2007). In non-formal and informal domains, knowledge is communicated using specific language which contains codes different from those in the formal domain. Differential specificity is required depending on the target agents. The spaces and channels are very wide-ranging. In Catalan universities, there are programmed actions like the campus 'prebat', research night, joint research, youth research campus and science week. These actions have a European reach with the actions Science is Wonderful, European Researchers' Night and Science for Everyone, which are aimed at the public and usually include primary and secondary school pupils and their families. Even though the function of these actions is linked to a vocation to serve on the part of the universities, many of them are designed to attract potential public to them and focus on sparking an interest in science, which has recently suffered a downturn.

Other spaces where non-formal science takes place are science museums and science centres, including zoos, planetariums and animal parks, all of which are examples of out-of-school environments. They have been recognized as having huge potential to engage students, especially since in-school learning has become increasingly anachronistic (Gardner 1991, Eshach 
2007). To give an example, the Science Gallery at Trinity College has redefined science communication to society by reproducing the lab in the gallery exhibitions where research needs are the key drivers (Merzagora, 2017). Indeed, playful exhibits and installations are new architectures of interaction that potentially facilitate dialogue in science museums through immediate apprehendability, physical interactivity, conceptual coherence and learner diversity (Allen 2004, Yaneva et al. 2009). It is difficult, however, for communication in these centres to have a large impact, given that on the one hand communication projects in non-formal domains do not take the curricular needs of students into account and even though the activities are designed to motivate pupils, not enough tools are generally provided for pupils to achieve autonomy support, structure (i.e., support of competence) and involvement (i.e., support of relatedness). Possible solutions are embedding narratives in museum exhibits that represent opposing citizen viewpoints on research and innovation and providing separate, safe environments and conversational guidance from researchers acting as facilitators. Communication is then based on providing information, giving instructions and making sure that children and parents have the opportunity to talk and ask questions (van der Meij et al. 2017).

Communicating non-formal science has also taken place in university laboratories where baccalaureate students are invited to have laboratory experiences. These experiences are often linked to formal activities that the students have done at school. Some projects based on non-formal education aim to revolutionise the way science is taught in schools as a complementary support for teaching science (Garner et al, 2014). The combination of formal school activities and non-formal laboratory experiences outside school for secondary school students was analysed in terms of achievement and motivation (Itzek-Grenlich et al., 2017) and it was found that lessons were more effective for producing gains in achievement, whereas the outof-school lab lessons established longer-lasting motivation.

Garner et al (2015) stated the importance of linking non-formal to formal education to promote education in sustainability in the classroom. In their study, they reported the willingness of secondary school teachers to introduce new teaching materials into their lessons. They stated that the experience improved students' personal attitudes towards sustainability. Plavsic and Dikovic (2016) analysed the acceptance of non-formal education among humanities, economics and educational sciences students, with the latter two groups being most receptive and students in the final years expressing more positive attitudes towards non-formal education than first-year students. Non-formal activities have also been found to be suitable for teaching difficult concepts on oceanography to very young students if they are presented in the right way (Merlino et al. 2015).

If in recent years, universities have participated in these activities in the non-formal domain through their research groups, ICEs and scientific communication units, then both universities and teaching centres need to define what must be communicated, who should communicate it and what the optimal spaces to disseminate science are. Neither cities nor universities and teaching centres generally have spaces which are purpose designed for carrying out scientific communication activities.

\section{Communication in science.}

From the analysis of scientific communication in formal and non-formal domains, different premises when communicating science can be derived. 
First, that it is better to communicate than not and that communication must be cross-cutting and must be done with transparency and quality. If, however, in acquiring the knowledge, ethical and sustainable criteria were applied, then its communication will intrinsically contain enough ethical, sustainable values. These reflections on ethics and sustainability must also be transmitted to the public and always adapted to each audience. These reflections are usually what attract the public and they demonstrate the need for and relevance of the research that is done at universities and research centres.

Second, communicating implies adapting the language, the spaces and the agents. Best practices in communication indicate that if the knowledge can be communicated universally, then the language must be adapted to the audience and the spaces where the communication takes place to be efficient. And, importantly, the agents responsible for the communication must be professionalised. The work of communication is a good opportunity for undergraduate students to learn to communicate in public and to adapt their language to their audience. These students, however, must be guided by researchers or professors who are experts in the subject. Surveys carried out among undergraduates who have developed research dissemination actions show that they employ different communication strategies. One of the most frequent is looking for analogies with everyday situations and processes that are well-known to the audience. The communicator thus reaches the audience, whose interest in the topic is awakened. Other communicators use the technique of asking questions to focus on the subject, some examples of which are, 'Have you heard of the case where...?' or 'Do you know if...?' or 'Do you know where...?' Undergraduate disseminators generally agree that communication evolves very positively as the event goes on. These sessions help them gain confidence, find new strategies and copy and put into practice some of their peers' strategies. Thus, we can see that in this case the learning experience can be beneficial for both the audience and the communicator. The researcher/educator who guides the undergraduates has a key role as he guides the students, easing them into developing the activity and allowing them to evolve by gradually giving them more autonomy and decision-making power. In this way, students who are capable of communicating very specific, concrete information at the beginning of the event feel confident to communicate the actions they have developed with their fellow classmates and even ask to do other activities by the end of it. At this point, all undergraduate students also agree that communicating was a very gratifying, positive experience and that the public appreciated the effort and showed enormous interest and a desire to participate.

Third, communicating implies differentiating between informing and giving an opinion, informing implies imparting knowledge with quality criteria, contextualising the knowledge and defining its social reach; in other words, the effect that specific scientific research could have once it is published. Giving an opinion, on the other hand, implies positioning oneself with respect to a possible application of the science, speculating on the consequences of the use of specific scientific research and generating economic and legal conflicts and responses, which are difficult to quantify.

Fourth, in activities of a non-formal type, the science broadcaster develops an activity in close proximity to the audience. This coming together of broadcaster and audience facilitates the transmission of science and also helps the scientist to avoid being stereotyped in terms of gender and physical appearance (Rocha Fernandes et al. 2017). Furthermore, this knowledge 
internalises a continuum between what students learn in school and what they learn in other contexts, be they formal or informal (Tudor 2017).

\section{Conclusions}

Formal, non-formal and informal education complement each other and mutually reinforce the lifelong learning process. Both non-formal and formal education are positive, not only for specific skills training, but also for developing the personalities of both the graduate students who are leading the activity and the student audience. The graduate students gain self-confidence and learn to communicate with others and the students are given the chance to learn about an issue authentically and thoroughly from various perspectives, while at the same time internalising several learning and communicating experiences.

Communicating science to different audiences and actors when its content and methodologies are solidly grounded mean that these audiences gain autonomy, while science itself gains objectivity. Furthermore, analyses can be configurated in terms of effectivity and service and, most importantly, science can define an ultimate concept of democracy, where communication in science is defined as a way of transformation.

\section{Bibliographical references}

- $\quad$ Allen, S. (2004). Designs for learning: Studying science museum exhibits that do more than entertain. Science Education, 88(S1), S17-S33.

- Colardyn, D., Bjornavold, J. (2004). Validation of formal, non-formal and informal learning: policy and practices in EU Member States. European Journal of Education, 39(1), 69-89.

- Entman, R.M. (1993). Framing: toward clarification of a fractured paradigm. Journal of Communication, 43(4), 51-58.

- Eshach, H. (2007). Bridging in-school and out-of-school learning: formal, non-formal, and informal education. Journal of Science Education and Technology, 16(2), 171-190.

- Gardner, H. (1991). The unschooled mind, Basic Books, New York.

- Garner, N., Hayes, S.M., Eilks, I. (2014). Linking formal and non-formal learning in science education. A reflection from two cases in Ireland and Germany. Journal of Education, 2(2), 10-31.

- Garner, N., Siol, A., Eilks, I. (2015). The potential of non-formal laboratory experiments for innovating the chemistry curriculum and promoting secondary school level students education for sustainability. Sustainability, 7, 1798-1818.

- Hooke, W. (2015). Reaffirming the social contract between science and society. EOS, 96.

- Itzek-Grenlich, H., Flunger, B., Vollmer, C., Nagengast, b., Rehm, M., Trautwein, U. (2017). Effectiveness of lab-work learning environments in and out of school: A cluster randomized study. Contemporary Educational Psychology, 48, 98-115.

- Merlino, S., Evangelista, R., Mantovani, C., Bianucci, M., Fieschi, R. (2015). Oceanography outreach and education in informal and non-formal learning environments. MTS/IEEE Oceans2015 Genova: Discovering sustainable ocean energy for a new world.

- Merzagora, M. (2017). Science centres and science engagement activities as research facilities: blurring the frontiers between knowledge production and knowledge sharing. Journal of Science Communication, 16(02), E.

- Owen, R., Macnaghten, P., Stilgoe, J. (2012). Responsible research and innovation: From science in society to science for society, with society. Science and Public Policy, 39, 751-60. 
- $\quad$ Pham, D. (2016). Public engagement is key for the future of science research. Nature partner journals. Science of Learning. 1, 16010.

- Plavsic, M., Dikovic, M. (2016). Students' attitudes toward formal education, non-formal and informal learning. Croatian Journal of Education, 18(1), 70-103.

- Rocha Fernandes, G.W., Rodrigues, A.M., Ferreira, C.A. (2017). Conception of the nature and technology: a study with children and youths in a non-formal science and technology education setting. Research in Science Education, 1-36, DOI: 10.1007/s1116.

- Russell, N. (2010). Communicating science: professional, popular, literary. Cambridge University Press, New York.

- $\quad$ Stilgoe, J., Lock, S.J., Wilsdom, J. (2014). Why should we promote public engagement with science?. Public Engagement in Science, 23(1), 4-15.

- Tudor, S.L. (2017). The role of non-formal and informal education in competences training-transversal competences. Proceedings of the 8th International Conference on Electronics, Computers and Artificial Intelligence, ECAI2016, 7861143.

- $\quad$ Van der Meij, M.G, Broerse, J.E.W., Kupper, F. (2017). RRI \& science museums; prototyping an exhibit for reflection on emerging and potentially controversial research and innovation. Journal of Science Communication, 16(04), A02.

- Vorderer, P. (2016). Communication and the good life: why and how our discipline should make a difference. Journal of Communication, 66, 1-12.

- Yaneva, A., Rabesandratana, T.M., Greiner, B. (2009). Staging scientific controversies: a gallery test on science museums' interactivity. Public Understanding of Science, 18, 79-90.

\section{CURRICULUM VITAE Jordi Colomer}

Dr. Jordi Colomer is a professor of Environmental Sciences in the Physics Department of the University of Girona. His main fields of interest include studies on innovative ecological processes for wastewater treatments, biogeomorphology in coastal areas and collaborative and reflective practices in higher education. $\mathrm{He}$ is an international evaluator for both research centres and education programmes. He is currently developing projects in non-formal education, most notably in collaboration with the international dance company Moviment Lantana.

\section{Teresa Serra}

Dr. Teresa Serra is an assistant professor of Environmental Sciences in the Physics Department of the University of Girona. Her main research interests are hydrodynamics, sediment transport, the ecology of wetlands and sustainable tertiary treatments based on biological processes. She is also interested in science experiences for non-formal education programmes. She is currently developing experiences in science with non-formal educational aims and is teaching undergraduate students to do practical demonstrations at fairs. She has taught courses to primary and secondary school teachers aimed at providing the tools to implement non-formal activities in combination with regular classroom lessons. 
